\title{
KARAKTERISTIK POMPA SENTRIFUGAL DENGAN VARIASI PENAMBAHAN JUMLAH FIN PADA BILAH TIPE SEMI OPEN
}

\author{
Ahmad Kurniawan \\ Teknik Mesin Konversi Energi, Fakultas Teknik, Universitas Negeri Surabaya \\ e-mail: ahmadkurniawan@mhs.unesa.ac.id
}

\begin{abstract}
Abstrak - Impeller merupakan salah satu bagian terpenting dari pompa sentrifugal yang dapat mempengaruhi performa pompa. Hal yang perlu dilihat dari performa pompa adalah nilai efisiensi, NPSH (Net Positive Suction Head), Head dan kebisingan dari pompa. Variasi riblet dengaan menambahkan fin pada sudu impeler dapat meningkatkan performa pompa, untuk mengetahui tingkat evisiensi performa pompa sentrifuggal perlu dilakukan variasi kecepatan motor dan temperatur air. Tujuan dari penelitian performa pompa sentrifugal agar dapat menganalisis pengaruh penambahan jumlah fin, variasi kecepatan dan temperaur terhadap performa pompa sentrifugal. Variabel bebas dalam penelitian ini adalah variasi penambahan jumlah fin pada impeller, variasi kecepatan dan variasi temparetur air. Dalam variasi pebambahan fin menggunakan impeller jumlah sudu 8 tanpa fin, variasi 1 fin, variasi 2 fin dan variasi 3 fin dengan ukuran riblet fin yaitu, lebar fin $(\mathrm{w})=2 \mathrm{~mm}$, jarak antar fin $(\mathrm{s})=3,4 \mathrm{~mm}$, tinggi fin $(\mathrm{h})=2 \mathrm{~mm}$. Variasi kecepatan putar motor yaitu $1500,2200 \mathrm{dan}$ $2800 \mathrm{rpm}$ sedangkan variasi temperatur air $30^{\circ} \mathrm{C}$ dan $70^{\circ} \mathrm{C}$. Dalam penelitian penambahan variasi jumlah fin pada sudu impeller ini memberi dampak positif pada kapasitas, head, npsh dan juga efisiesi pompa. Untuk impeller dengan variasi penambahan 3 fin mendapatkan nilai kapasitas yaitu $65 \mathrm{lpm}$, dengan nilai head $17 \mathrm{~m}$ didapatkan pada putaran motor 2800 rpm, sedangkan nilai npsh tertinggi $13,5 \mathrm{~m}$ didapatkan pada putaran motor $1500 \mathrm{rpm}$, pada suhu $30^{\circ} \mathrm{C}$, untuk nilai efisiensi tertinggi pompa yaitu $54 \%$ pada kecepatan $2800 \mathrm{rpm}$, pada suhu $30^{\circ} \mathrm{C}$
\end{abstract}

Kata Kunci- pompa sentrifugal; riblet; npsh; efisiensi.

\begin{abstract}
Impeller is one of the most important part of a centrifugal pump which can affect pump performance. The thing that needs to be seen from the performance of the pump is its value of efficiency, NPSH (Net Positive Suction Head), Head and noise from the pump. Riblet variations by adding fins to the impeller blade can improve pump performance, to find out the efficiency level of centrifugal pump performance, it is necessary to do variations in motor speed and water temperature. The purpose of the performance research of centrifugal pumps is to be able to analyze the effect of increasing the number of fins, variations in speed and temperature for centrifugal pump performance. The independent variable in this study is the variation in the number of fins added to the impeller, variations in speed and variations in water temperature. In addition to fin variations, the impeller uses 8 blades without fins, 1 fin variation, 2 fin variations and 3 fin variations with fin size ie, fin width $(w)=2 \mathrm{~mm}$, distance between fin $=3.4 \mathrm{~mm}$, fin height $(\mathrm{h})=2 \mathrm{~mm}$. Motor rotation speed variations are 1500 , 2200 and $2800 \mathrm{rpm}$ while water temperature variations $30^{\circ} \mathrm{C}$ and $70^{\circ} \mathrm{C}$. In this study the addition of variations in the number of fin on the impeller blade has a positive impact on capacity, head, NPH and also pump efficiency. For impellers with the addition of 3 fin variations, the capacity value is $65 \mathrm{lpm}$, with a $17 \mathrm{~m}$ head value obtained at $2800 \mathrm{rpm}$ motor rotation, while the highest NPH value of $13.5 \mathrm{~m}$ was obtained at $1500 \mathrm{rpm}$, at $30{ }^{\circ} \mathrm{C}$, for the highest efficiency pump value, $54 \%$ at $2800 \mathrm{rpm}$, at $30{ }^{\circ} \mathrm{C}$.
\end{abstract}

Keywords - centrifugal pump, riblet, NPSH, efficiency.

\section{PENDAHULUAN}

Pompa merupakan peralatan mekanis yang banyak digunakan di dunia industri maupun rumah tangga. Pompa pada dasarnya berfungsi untuk menaikkan tekanan fluida dari fluida bertekanan rendah menjadi fluida bertekanan tinggi, pada umumnya pompa banyak digunakan untuk mengalirkan fluida dari dataran rendah ke dataran yang lebih tinggi dan juga sebagai penguat laju aliran saat melewati hambatanhambatan berupa belokan, hambatan berupa perbedaan tekanan dan hambatan berupa ketinggian.

Pompa sentrifugal banyak digunakan karena pengoperasiannya yang mudah serta pemeliharaan yang tidak terlalu mahal. Pompa sentrifugal mampu mengalirkan fluida sehingga fluida mampu melewati hambatan dan menaikkan tekanan dengan cara mengonversikan energi mekanik menjadi tekanan atau energi mekanik, tekanan pada pompa meningkat sehingga menghasilkan bagian dengan tekanan rendah (lebih rendah dari tekanan atmosfer) pada sisi hisap pompa (suction) dan tekanan tinggi pada sisi keluaran pompa(discharge), rendahnya tekanan pada sisi hisap membuat fluida mengalir masuk secara aksial melalui sisi hisap yang berada di tengah pompa kemudian fluida akan berputar bersama dengan putaran sudu atau impeler pompa.

Penurunan performa pompa juga bisa terjadi karena adanya kavitasi, kavitasi merupakan adanya gelembung gelembung udara yang terperangkap di dalam fluida pada saat proses pengoperasian pompa, adanya gelembung udara yang terperangkap dapat mengakibatkan menurunnya daya hisap 
sehingga berpengaruh juga pada tekanan yang di hasilkan pompa. Kavitasi dipengaruhi oleh adanya penurunan NPSH (Net Positive Suction Head).

Penambahan jumlah fin pada permukaan sudu impeler akan berfungsi sebagai bantalan dari aliran fluida, karena fluida akan terlebih dahulu memenui ruang pada celah fin sehingga fluida yang mengalir akan berkurang drag reduction yang tentunya akan berdampak positif terhadap kenaikan kapasitas pompa.

Pada penelitian terdahulu sudah banyak yang melakukan penelitian tentang kinerja dari berbagai model impeller, penelitian lanjutan dimaksudkan supaya nantinya akan di dapatkan hasil data yang lebih efisien sehingga dapat memperkecil kerugian dalam pengoperasian pompa.

Pada penelitian sebelumnya yang dilakukan oleh Sembada (2017), penelitian mengenai variasi jumlah bilah pada impeller. Dari penelitian tersebut disimpulkan bahwa jumlah sudu 8 pada impeler menghasilkan kapasitas paling tinggi dalam prosesnya tetapi nilai NPSHa mengalami kenaikan.

Pada penelitian yang dilakukan oleh Delly (2009), penelitian ini tentang pengaruh suhu fluida terutama air terhadap kavitasi, Temperatur sangat berpengaruh dalam kemunculan kavitasi. Rendahnya nilai viskositas menyebabkan tekanan uap jenuh air menjadi tinggi sehingga menyebabkan terjadinya kavitasi.

Pada penelitian Musyafa (2015), dalam penelitian ini tentang efisiensi dan kapasitas pompa. Dengan menambahkan kecepatan motor dalam proses ini dapat meningkatkan efisiensi dan kapasitas air dan dibantu dengan penambahan jumlah sudu pada impeller.

Pada penelitian Heidarian, et.al. (2017) dalam penelitian ini menunjukkan bahwa riblet lebih efisien dari plat biasa. Riblet ini menggunakan model seperti sirip ikan hiu. Dengan adanya riblet bentuk sirip ikan hiu ini menghasilkan nilai drag force lebih rendah dari pada drag reduction sehingga gesekan pada permukaan bisa dikurangi dibantu dengan penggunaan ratio $\mathrm{h} / \mathrm{s}$ menentukan jarak impeller.

Penelitian Nugroho, dkk (2013) mengenai "Studi Eksperimental Vertical Axis Wind Turbine Tipe Savonius dengan Variasi Jumlah Fin pada Sudu" disimpulkan bahwa dengan variasi jumlah fin pada sudu dapat meningkatkan performa turbin.

Agar data hasil pengujian dapat dihitung dan dapat dianalisa dalam bentuk grafik, maka diperlukan beberapa parameter dari performa pompa sentrifugal yaitu

1. Head Pompa adalah tinggi tekan yang harus dilakukan oleh pompa untuk mengalirkan fluida yang merupakan jumlah perbedaan pressure head di sisi suction dan disscharge dengan head loss yang terjadi ditambah dengan statik head demgan velocity head, dapat dihitung dengan persamaan bernouly sebagai berikut:

$$
\mathrm{H}=\frac{P_{\underline{2}}-P_{1}}{\rho}+\frac{P_{g^{2}}-v_{12}}{2 g}+\left(Z_{2}-Z_{1}\right)+H_{L T}
$$

2. Net Positive Suction Head (NPSH) adalah suatu nilai yang menunjukan adanya tingkat kavitasi pada aliran fluida yang juga bisa menjadi parameter tingkat performa dari pompa sentrifugal yang dapat diformulasikan sebagai berikut:

$h_{s v}=\frac{p_{a}-p_{v}}{\rho}+\frac{p_{s}}{\rho}+z_{p s}+\frac{p^{g}}{2 g}$

3. Water Horse Power (WHP) adalah nilai kebutuhan pompa untuk menangani cairan yang dipompakan didapatkan dengan menggunakan rumus sebagai berikut:

$\mathrm{WHP}=\rho \times \mathrm{g} \times \mathrm{Q} \times \mathrm{H}$.

4. BHP (Break Horse Power) adalah suatu nilai dari perhitungan daya motor listrik untuk menggerakkan pompa sentrifugal, dapat di formulasikan sebagai berikut:

BHP $=$ Efisiensi motor $\mathrm{x}$ Pm

5. Efisiensi berdasakan pada daya fluida (water horse power) yang diterima air terhadap daya poros pompa (brake horse power) dan dapat dirumuskan sebagai berikut:

$\eta=\frac{W H P}{B H P}$

\section{METODE}

A. Variabel penelitian

Variabel-variabel yang digunakan dalam penelitian ini dapat diklasifikasi menjadi 3 yaitu

\section{Variabel Bebas (Independent Variable)}

Variabel bebas dalam penelitian "Uji Eksperimen Pengaruh Penambahan Jumlah Fin Pada Bilah Impeler Yang Berjumlah 8 Pompa Sentrifugal" adalah sebagai berikut :

a. Putaran poros pompa sentrifugal $1500 \mathrm{rpm}, 2200$ rpm, $2800 \mathrm{rpm}$.

b. Temperatur fluida yang dipompakan $30^{\circ} \mathrm{C}$ dan $70^{\circ} \mathrm{C}$.

c. Bentuk riblet fin : lebar fin $(\mathrm{w})=2 \mathrm{~mm}$, jarak $\operatorname{antar} f i n(\mathrm{~s})=3,4 \mathrm{~mm}$, tinggi fin $(\mathrm{h})=2 \mathrm{~mm}$.

d. Jumlah bilah pada impeller adalah 8 , dengan variasi penambahan $1 \mathrm{fin}, 2 \mathrm{fin}$ dan $3 \mathrm{fin}$. 

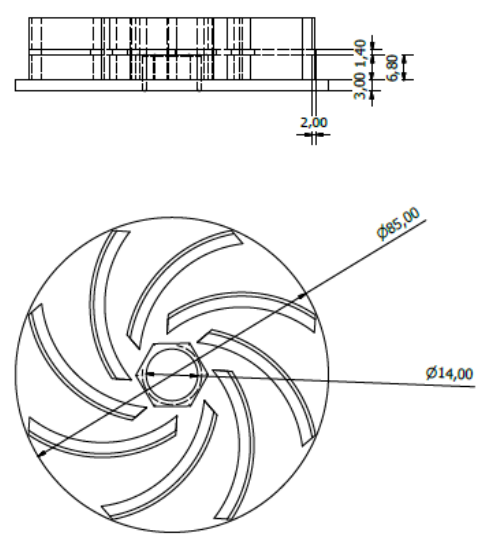

Gbr. 1 Impeller variasi 1 fin
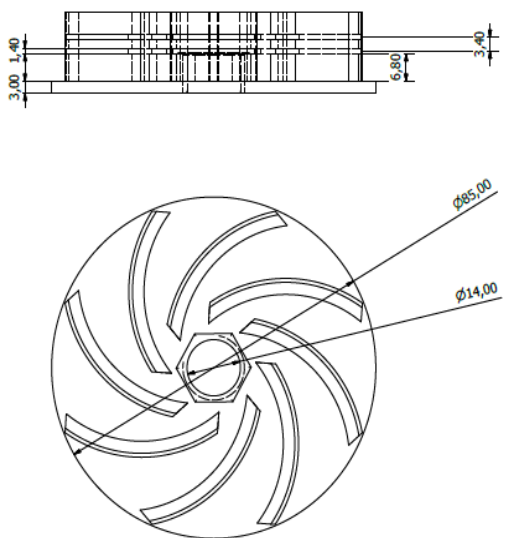

Gbr. 2 Impeller variasi 2 fin
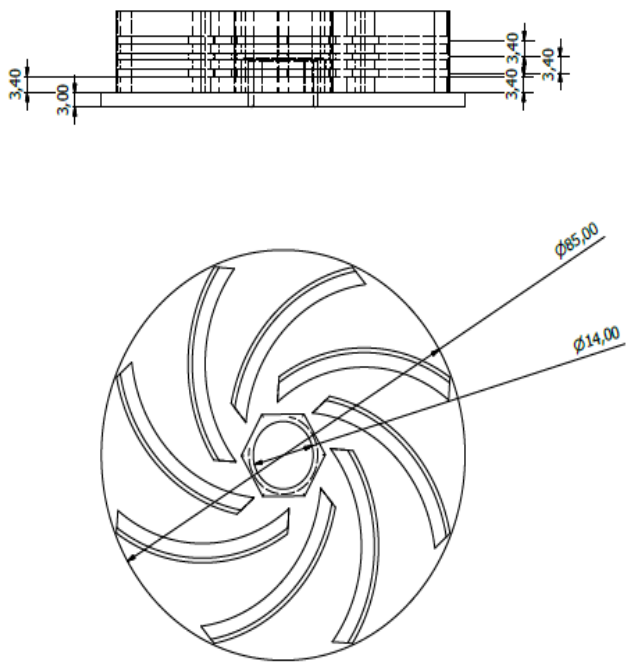

Gbr. 3 Impeller variasi 3 fin
2. Variabel Terikat (Dependent Variable)

Variabel terikat dalam penelitian ini adalah tekanan section, tekanan discharge dan kapasitas pompa.

3. Variabel Kontrol (Control Variable)

Variable kontrol dalam penelitian ini adalah jenis fluida yang diganakan yaitu air.

B. Instrumen Dan Alat Penelitian

Alat penelitian adalah alat yang digunakan dalam penelitian, dalam penelitian ini alat-alat yang digunakan adalah sebagai berikut:

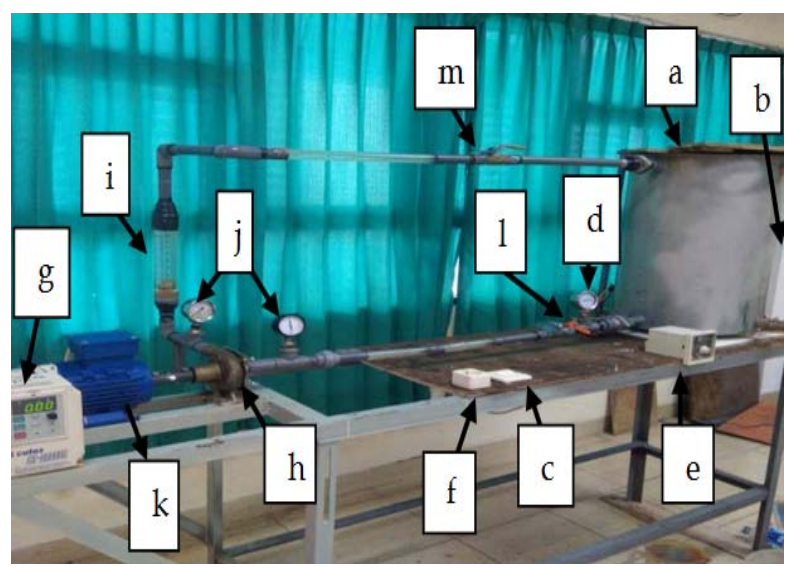

Gbr. 4 Rangkaian instrumen penelitian

'Keterangan instalasi:
a. reservoir
b. Level ketinggian air reservoir
c. Stop kontak
d. Thermometer
e. Thermocontrol
f. Saklar
g. Inverter
h. Rumah pompa
i. Flowmeter
j. Pressure gange
k. Motor
1. Valve sisi suction
$\mathrm{m}$. Valve sisi discharge

\section{HASIL DAN DISKUSI}

A. Pengaruh Temperatur Air, Kecepatan Putar Pompa, dan Jumlah Bilah Impeller Terhadap NPSH Pompa. 


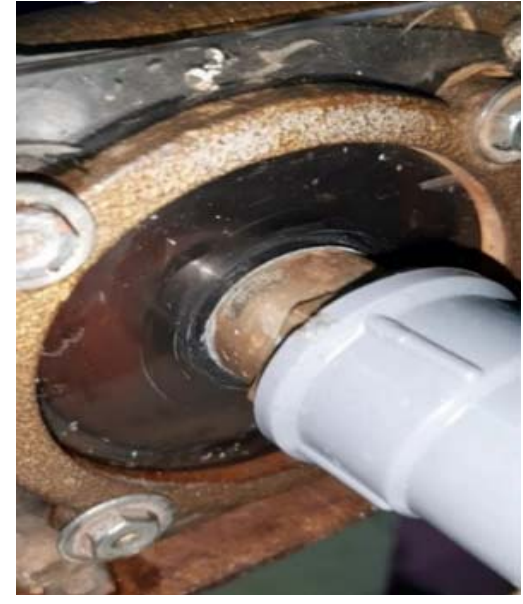

Gbr. 5 Variasi impeller 3 fin sebelum terjadi kavitasi kecepatan $2800 \mathrm{rpm}$ dan suhu $30^{\circ} \mathrm{C}$

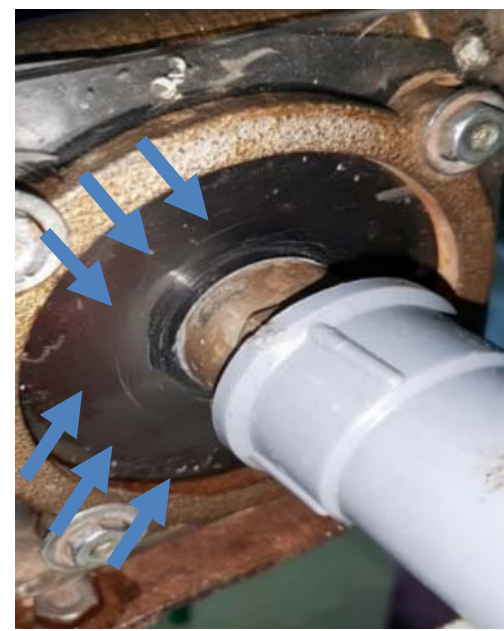

Gbr. 6 variasi impeller 3 fin saat terjadi kavitasi kecepatan $2800 \mathrm{rpm}$ dan suhu $70^{\circ} \mathrm{C}$

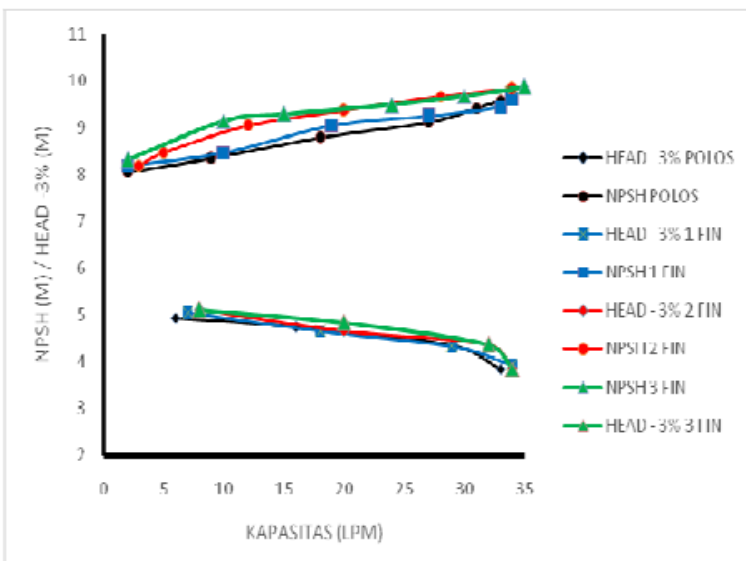

Gbr. 7 NPSH pada kecepatan $1500 \mathrm{rpm}$ temperatur $30^{\circ} \mathrm{C}$

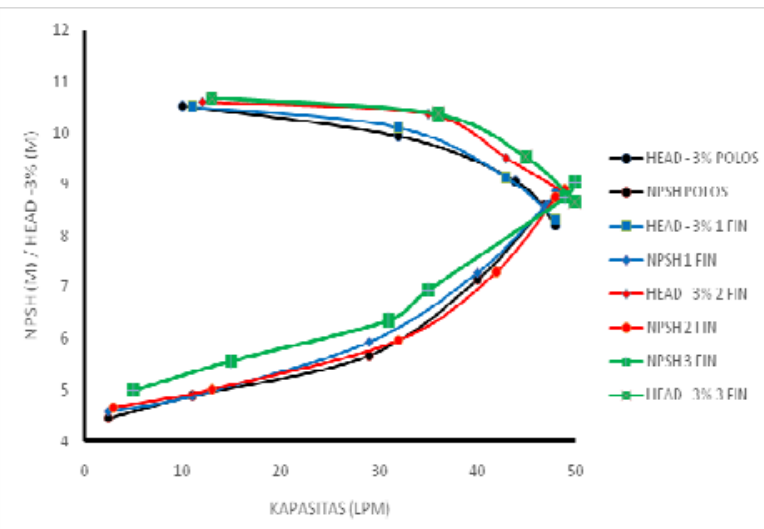

Gbr. 8 Grafik NPSH pada kecepatan 2200 rpm temperatur $30^{\circ} \mathrm{C}$

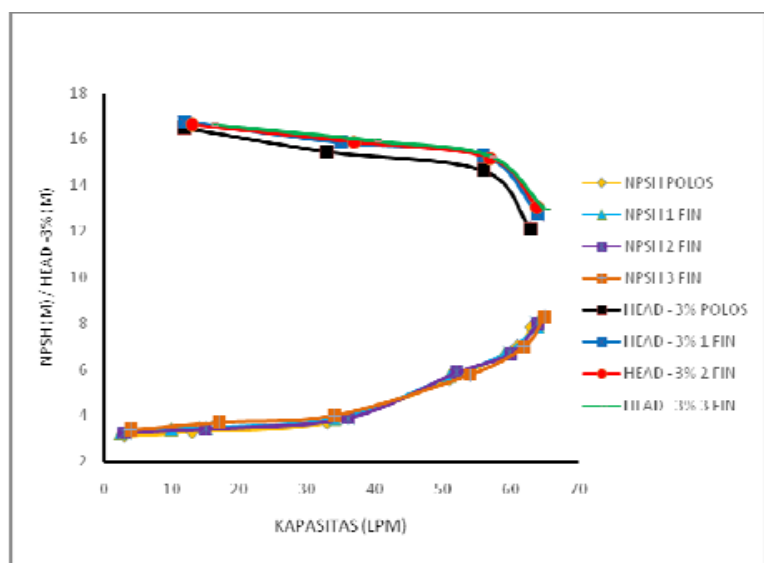

Gbr. 9 Grafik NPSH pada kecepatan 2800 rpm temperatur $30^{\circ} \mathrm{C}$

Pada gambar grafik 7 dapat di lihat bahwa keempat impeller tidak mengalami kavitasi pada temperatur $30^{\circ} \mathrm{C}$ dan kecepatan $1500 \mathrm{rpm}$, ini dikarenakan nilai NPSHa lebih besar dari nilai NPSHr. Pada gambar grafik 8 berada pada kecepatan 2200 RPM dan pada gambar grafik 9 kecepatan 2800 RPM sudah mengalami kavitasi karena pada kecepatan ini mengalami penurunan tekanan suction, semakin tinggi kecepatan maka tekanan suction semakin turun yang mengakibatkan nilai NPSHa semakin turun sehingga munculnya kavitasi semakin tinggi.

Semakin tingginya kecepatan putar motor listrik menyebabkan debit air yang masuk di dalam pompa semakin besar tetapi aliran fluida menjadi turbulensi. Terjadinya turbulensi mengakibatkan munculnya gaya gesekan antara fluida dengan permukaan rumah pompa sehingga menyebabkan adanya energi tambahan di dalam rumah pompa sehingga munculnya kavitasi di dalam rumah pompa (volute).

Jadi, dapat di simpulkan bahwa munculnya kavitasi akibat dari bertambahnya kecepatan putar motor. 
B. Analisis Pengaruh Temperatur Air, Kecepatan Putar Pompa, dan Variasi Penambahan Jumlah Fin Pada Impeller Terhadap Efisiensi Pompa.

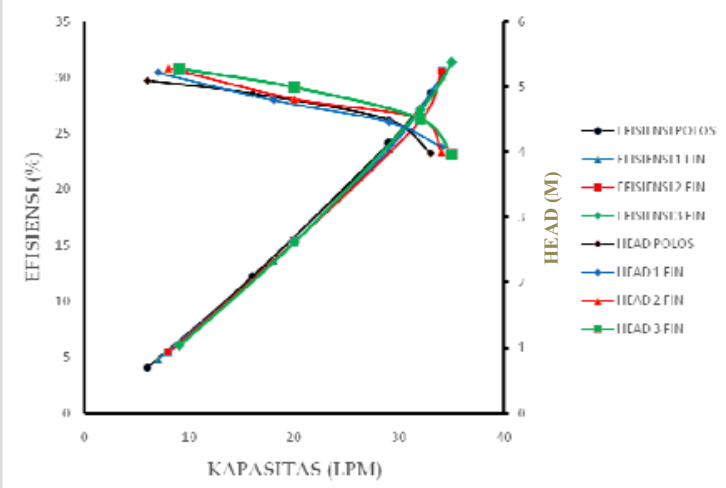

Gbr. 10 Grafik efisiensi pada kecepatan 1500 rpm temperatur $30^{\circ} \mathrm{C}$

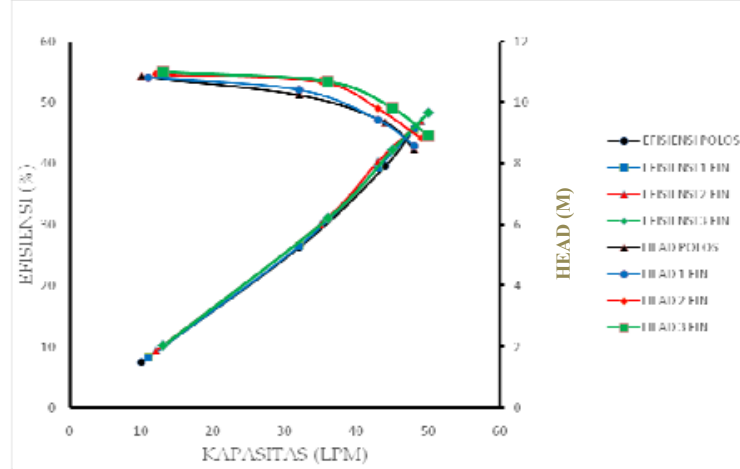

Gbr. 11 Grafik efisiensi pada kecepatan $2200 \mathrm{rpm}$ temperatur $30^{\circ} \mathrm{C}$

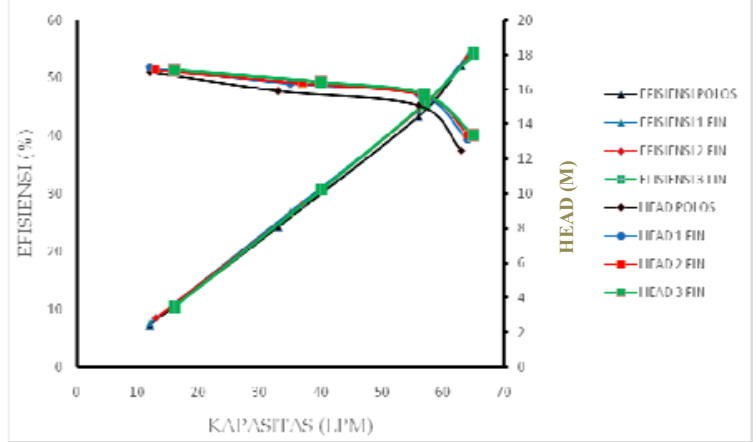

Gbr. 12 Grafik efisiensi pada kecepatan $2800 \mathrm{rpm}$ temperatur $30^{\circ} \mathrm{C}$

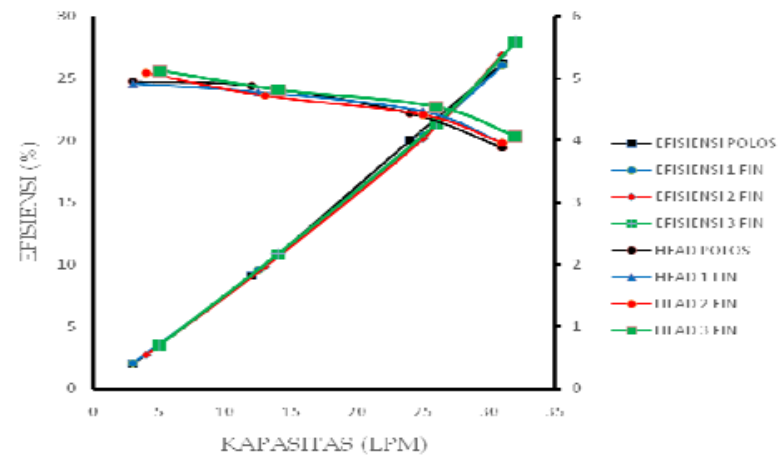

Gbr. 13 Grafik efisiensi pada kecepatan 1500 rpm temperatur $70^{\circ} \mathrm{C}$

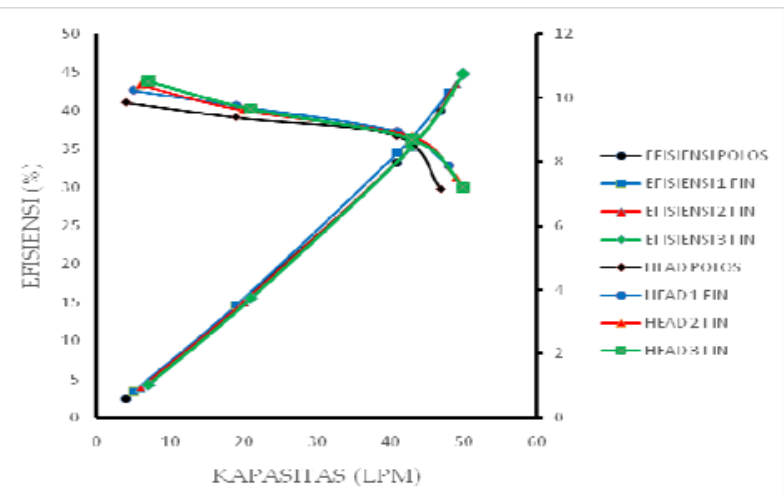

Gbr. 14 Grafik efisiensi pada kecepatan $2200 \mathrm{rpm}$ temperatur $70^{\circ} \mathrm{C}$

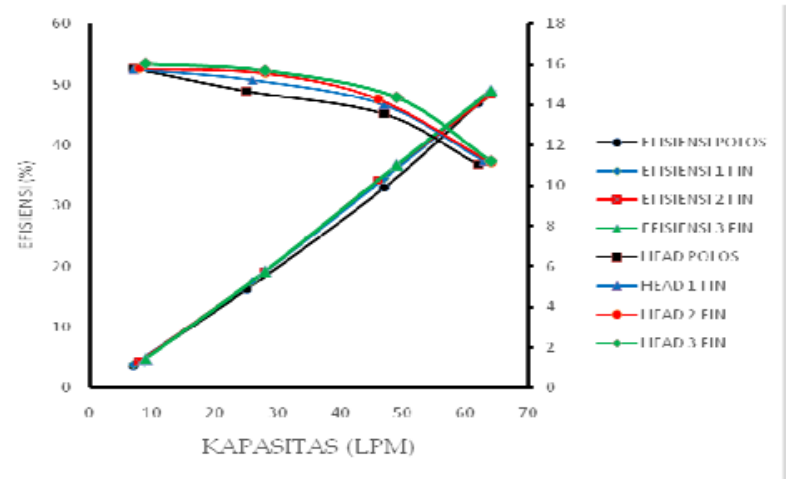

Gbr. 15 Grafik efisiensi pada kecepatan $2800 \mathrm{rpm}$ temperatur $70^{\circ} \mathrm{C}$

Dari gambar grafik-grafik di atas dapat diamati bahwa semakin tinggi kecepatan putar motor maka nilai efisiensi pompa semakin naik karena debit air yang masuk ke dalam pompa semakin besar, akibatnya kapasitas yang hisap pompa semakin besar sehingga efisiensi naik. efisiensi yang tertinggi berada di impeller dengan variasi 3 fin pada kecepatan 2800 RPM yaitu 54\%. Naiknya kecepatan motor berpengaruh terhadap nilai kapasitas pompa dan 
head. Dengan adanya penambahan variasi 3 fin berpengaruh pada naiknya efisiensi pompa, penambahan variasi 3 fin mampu menaikkan efisiensi pompa jika dibandingkan dengan bilah impeller polos, juga penambahan variasi 1 fin dan 2 fin. Sifat dari penambahan variasi 3 fin ini adalah mampu mengurangi gesek pada lintasan aliran sehingga dapat mengurangi hambatan terkait dengan berkurangnya turbulensi aliran silang secara signifikan. Mekanisme reduksi tegangan geser oleh riblet adalah riblet menghambat gerakan cross-flow sehingga aliran turbulensi dapat dikurangi dengan adanya penambahan variasi 3 fin.

Nilai head tertinggi $17 \mathrm{~m}$, kapasitas tertinggi yaitu 65 $1 \mathrm{pm}$ dan efisiensi tertinggi $54 \%$ didapatkan pada kecepatan $2800 \mathrm{rpm}$ dan temperature air $30^{\circ} \mathrm{C}$, sedangkan pada temperatur air $70{ }^{\circ} \mathrm{C}$ didapatkan nilai head tertinggi $16 \mathrm{~m}$, kapasitas tertinggi yaitu $64 \mathrm{lpm}$ dan efisiensi tertinggi 49\% pada kecepatan $2800 \mathrm{rpm}$, ini disebabkan karena adanya kenaikan temperatur air yang menyebabkan air mendidih dan menyebabkan munculnya gelembung gelembung udara pada air sehingga pada saat proses pemompaan yang terhisap masuk kedalam rumah pompa tidak murni air melainkan air yang bercampur dengan gelembung gelembung udara yang menyebabkan munculnya kavitasi.

Jadi, dapat di simpulkan bahwa semakin bertambahnya kecepatan putar motor maka nilai efisiensi akan semakin tinggi, tetapi kenaikan temperatur air akan menyebabkan penurunan efisiensi karena akan mempercepat adanya kavitasi pada pompa.

C. Analisis Pengaruh variasi penambahan jumlah Fin pada Impeller dan Variasi Kecepatan Putaran Terhadap Kebisingan Pompa.

Pada tabel 1 di bawah, menunjukkan data kebisingan yang dihasilkan oleh adanya variasi penambahan jumlah Fin pada impeller dan variasi kecepatan putaran.

Tabel 1 Data Kebisingan Pada Variasi penambahan jumlah fin pada Impeller dan Variasi Kecepatan Putaran

\begin{tabular}{|c|c|c|c|c|}
\hline \multirow{2}{*}{$\begin{array}{c}\text { kecepatan } \\
\text { (RPM) }\end{array}$} & \multicolumn{4}{|c|}{ Kebisingan (dB) } \\
\cline { 2 - 5 } & $\begin{array}{c}\text { impeller } \\
\text { polos }\end{array}$ & $\begin{array}{c}\text { impeller 1 } \\
\text { fin }\end{array}$ & $\begin{array}{c}\text { impeller 2 } \\
\text { fin }\end{array}$ & $\begin{array}{c}\text { impeller 3 } \\
\text { fin }\end{array}$ \\
\hline 1500 & 68,2 & 68,3 & 68,2 & 68,2 \\
\hline 2200 & 69,3 & 69,2 & 69,2 & 69,2 \\
\hline 2800 & 71,8 & 71,7 & 71,7 & 71,7 \\
\hline
\end{tabular}

Dari tabel 1 di atas, selanjutnya dibuat grafik yang akan dianalisis sebagai berikut:

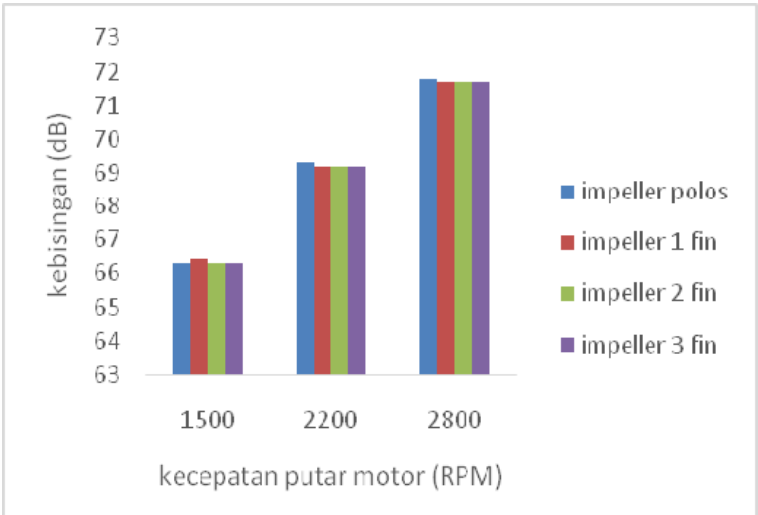

Gbr 16 Grafik kebisingan yang ditimbulkan oleh variasi penambahan jumlah fin pada impeller dan variasi kecepatan putaran

Pada grafik diatas menunjukkan bahwa impeller polos mengalami kebisingan yang paling tinggi yaitu mencapai $72,7 \mathrm{~dB}$ pada kecepatan putar motor 2800 RPM sedangkan kebisingan yang paling rendah terdapat pada impeller dengan variasi 3 fin pada kecepatan putar motor 1500 RPM. Dari grafik diatas bisa disimpulkan bahwa semakin besar kecepatan putar motor maka semakin besar juga kebisingan pompa sehingga disarankan untuk tidak mendengarkan lebih dari 8 jam.

\section{KESIMPULAN}

Berdasarkan pada penelitian yang telah dilakukan tentang pengaruh temperatur air, kecepatan putaran pompa, dan variasi penambahan jumlah fin pada bilah terhadap karakteristik pompa sentrifugal semi open, maka dapat disimpulkan sebagai berikut:

a. Adanya variasi penambahan jumlah fin pada impeller dapat meningkatkan nilai head, kapasitas air yang dihasilkan, efisiensi pompa dan juga kebisingan pompa, tetapi hal itu berbanding terbalik untuk NPSH pompa. Head teringgi yaitu $17,1 \mathrm{~m}$, kapasitas tertinggi yaitu 65 lpm, dan efisiensi tertinggi yaitu $54 \%$ didapatkan pada impeller dengan variasi 3 fin dengan putaran motor 2800 rpm pada suhu $30^{\circ} \mathrm{C}$. Untuk kebisingan tertinggi yaitu 71,8 $\mathrm{dB}$ didapatkan pada impeller polos. Sedangkan untuk NPSH tertinggi yaitu $13,5 \mathrm{~m}$ didapatkan pada impeller variasi 3 fin dengan putaran motor $1500 \mathrm{rpm}$ pada suhu $30^{\circ} \mathrm{C}$.

b. Adanya variasi penambahan temperatur air pada pompa maka akan berpengaruh terhadap nilai head, kapasitas air, NPSH dan efisiensi pompa. pada temperatur $30^{\circ} \mathrm{C}$ didapatkan Head 17,1 m, kapasitas 65 lpm, NPSH 13,5 m, dan efisiensi $54 \%$, untuk temperatur $70^{\circ} \mathrm{C}$ didapatkan nilai Head 16 m, kapasitas 64 lpm, NPSHa tertinggi yaitu $7,1 \mathrm{~m}$ dan efisiensi $49 \%$, bisa disimpulkan semakin tinggi temperatur air maka nilai head, kapasitas, NPSH dan efisiensi menurun. 


\section{REFERENSI}

[1] Ali, Imad S and Al-Fatlawie, Noor H. 2011. “ Drag Reduction In Turbulent Flow Using Different Kinds of Riblets ". Conference Proceeding. 457-469

[2] Bixler, G. D., \& Bhushan, B. 2012. "Biofouling: lessons from nature. Philosophical Transactions of the Royal Society of London A Mathematical". Physical and Engineering Sciences. 2381-2417

[3] Delly, Jenny. 2009. "Pengaruh Temperatur Terhadap Terjadinya Kavitasi Pada Sudu Pompa Sentrifugal”. Dinamika Jurnal Ilmiah TM. Vol. 01(01): ISSN 2085-8817

[4] Heidarian, A., Ghassemi, H., Liu P. 2017. "Numerical Analsys of The Effects of Riblets on Drag Reduction of a Flat Plate ". Applied Fluid mechanic. Vol. $\mathrm{x}(\mathrm{x})$ : pp $\mathrm{x}-\mathrm{x}, 200 \mathrm{x}$

[5] Junaidi, Fathona Fajri. 2014. " Analisis Distribusi Kecepatan Aliran Sungai Musi (Ruas Jembatan Ampera Sampai Dengan Pulau Kemaro)". Jurnal Teknik Sipil dan Lingkungan. Vol. 2(03)

[6] Karasik, Igor J., William C. Krutzsc, Warren H. Frase, Joseph Messina. 2001. Pump Handbook $3^{\text {th }}$ edition. McGraw Hillbokk: Amerika Serikat

[7] Kurdi, Ojo dan Arijanto. 2007. “Aspek Torsi dan Daya pada Mesin Sepeda Motor 4 Langkah dengan Bahan Campuran Premium Methanol". Jurusan Teknik Mesin FT - UNDIP. Vol. 9(02)

[8] Musyafa, Achmad Aliyin. 2015. "Pengaruh Jumlah Sudu Sentrifugal Impeller Terhadap Kapasitas dan Efisiensi Pompa Sentrifugal". Jurusan Teknik Mesin. Vol. 03 (03) : hal. 136-144

[9] Nouwen, A dan Amir, B.S. 1981. Pompa 1. Jakarta: Bhatara Karya Aksara
[10] Nugroho, Gunawan. Hantoro, Ridho. Hasan, Dwi Sandra. 2013. "Studi Eksperimental Vertical Axis Wind Turbine Tipe Savonius dengan Variasi Jumlah Fin pada Sudu". Mekanika. Vol. 2 (2) : hal. 2337-3539

[11] Sembada, Satrya. 2017. "Pengaruh Jumlah Bilah Centrifugal Impeller Terhadap NPSH Pompa". Jurusan Teknik Mesin. Vol. 05(01): hal. 101110

[12] Sihite, Alexander Nico P., Nasution, A. Halim. 2013. "Analisis Kerugian Head Pada Sistem Perpipaan Bahan Bakar HSD PLTU Sicanang Menggunakan Program Analisis Aliran Fluida ". Jurnal E Dinamis. Vol. 04(04): ISSN 2338-1035

[13] Siregar, Indra Herlamba. 2013. Pompa setrifugal. Surabaya: University Press

[14] Sugiyono. 2010. Metode Penelitian Kuantitatif Kualitatif dan R\&D. Penerbit Alfabeta

[15] Sularso dan Tahara, Haruo. 2000. Pompa dan Kompresor. Jakarta: Penerbit Pradnya Paramitha.

[16] Tim Penulis. 2004. Buku Pedoman Penulisan dan Ujian Skripsi Unesa. Surabaya: Unesa.

[17] Wibowo, Priyo Ari. 2013. "Analisis Penurunan Head Losses Pada Belokan Pipa $180^{\circ}$ Dengan variasi Non Tube Bundle, Tube Bundle 0,25 Inchi dan Tube Bundle 0,5 Inchi”. Mechanical Enginering Faculty Jember Univercity. Vol. 01(01): ISSN 2085-8817

[18] Yohana, Eflita dan Nugroho, Ari. 2016. “ Analisa Perhitungan Efisiensi Circulating Water Pump 76LKSA-18 Pembangkit Listrik Tenaga Uap Menggunakan Metode Analitik”. Rotasi. Vol. 18(01): 8-12 